\title{
Experimental study of chemiluminescence in UV and VIS range at hydrogen-oxygen mixtures ignition
}

\author{
Alexander Eremin ${ }^{1}$, Mayya Korshunova ${ }^{1,2}$, and Ekaterina Mikheyeva ${ }^{1,2},{ }^{*}$, \\ ${ }^{1}$ JIHT RAS, 125412 Moscow, Russia \\ ${ }^{2}$ BMSTU, 105005 Moscow, Russia
}

\begin{abstract}
The nonequilibrium radiation in the spectral range of 210-415 $\mathrm{nm}$ at ignition of a $10 \%$ stoichiometric hydrogen-oxygen mixture with additives of combustion inhibitors diluted with argon behind shock waves was registered. The detected chemiluminescence is presumably attributed to electronically excited $\mathrm{H}_{2} \mathrm{O}^{*}$ and $\mathrm{H}_{2} \mathrm{O}_{2}{ }^{*}$. Instead of the expected quenching of excited radicals and molecules in the ignition zone, with the addition of halogenated hydrocarbons inhibitors, the increase of radiation, particularly in the range of $330-415 \mathrm{~nm}$, was observed. The possible reasons of this phenomenon are discussed.
\end{abstract}

\section{Introduction}

It is well known that the zone of ignition of hydrogen-oxygen mixtures is accompanied by the intense UV emission, usually attributed to excited $\mathrm{OH}^{*}$ radicals. At the same time the other electronically excited radicals and molecules $\left(\mathrm{HO}_{2}{ }^{*}, \mathrm{H}_{2} \mathrm{O}^{*}, \mathrm{H}_{2} \mathrm{O}_{2}{ }^{*}\right)$ can make an important contribution to the observed emission spectra [1-4]. It is assumed that the intensity of overequilibrium emission at ignition is an indicator of the rate of development of the ignition process. Therefore, when studying extremely topical problems of inhibiting the ignition of hydrogen, recording of nonequilibrium UV emission is usually one of the main diagnostic methods. In previous works [5, 6], it was shown that halogenated hydrocarbons are the effective inhibitors of hydrogen ignition and substantially increase the ignition delay times of hydrogen-oxygen mixtures behind shock waves. In a recent paper [7] it was suggested that the one of the possible inhibition mechanisms is the resonance quenching of excited states of active radicals, in particular, the peroxyl radical $\mathrm{HO}_{2} *$, which plays a key role in chain branching upon ignition of hydrogen-oxygen mixtures $\mathrm{H}+\mathrm{O}_{2} \rightarrow$ $\mathrm{HO}_{2} * \rightarrow \mathrm{O}+\mathrm{OH}, \mathrm{H}+\mathrm{O}_{2}+\mathrm{M} \rightarrow \mathrm{HO}_{2}+\mathrm{M}[8,9]$, in collisions with molecules of inhibitors.

Therefore, the goal of this work is to analyse the effect of halogen-containing combustion inhibitors $\left(\mathrm{CCl}_{4}, \mathrm{C}_{2} \mathrm{~F}_{4} \mathrm{Br}_{2}\right)$ addition, which effect on hydrogen ignition was previously studied in detail by the authors $[5,6]$, as well as inert $\mathrm{CO}_{2}$ addition, on the level of nonequilibrium UV radiation in spectral range from 210 up to $415 \mathrm{~nm}$ at ignition of

\footnotetext{
${ }^{*}$ Corresponding author: ekaterina.mikheyeva@gmail.com
} 
stoichiometric hydrogen-oxygen mixture with additives of combustion inhibitors behind shock waves.

\section{Experimental}

The experiments were carried out in a standard shock tube equipped with modern optical diagnostic methods. The ignition behind the reflected shock wave was detected with the use of piezoelectric pressure sensors, as well as nonequilibrium radiation was detected with a photomultiplier, at $310 \pm 5 \mathrm{~nm}$ (which corresponds to the electronic transition of the $\mathrm{OH} *$ radical). Spectral emission at wavelengths from 210 up to $415 \mathrm{~nm}$ was measured with the help of an Acton Research Cooperation SpectraPro 150 diffraction monochromator and photomultiplier Hamamatsu H6780-04 with spectral resolution of $\pm 4 \mathrm{~nm}$. The spectral resolution is checked using mercury line measurements. The quantum efficiency of the entire setup is calibrated using a tungsten lamp with a known spectral emissivity. The investigated spectral range is characteristic for the emission of electronically excited radicals and molecules $\mathrm{HO}_{2}{ }^{*}, \mathrm{H}_{2} \mathrm{O}^{*}, \mathrm{H}_{2} \mathrm{O}_{2} *[10,11]$. The parameters of the mixtures studied, as well as the ranges of temperatures and pressures behind the reflected shock waves, are given in the table 1.

Table 1. The experimental mixtures and parameters.

\begin{tabular}{|c|c|c|c|c|c|c|c|}
\hline Mixture title & $\mathrm{H}_{2}, \%$ & $\mathrm{O}_{2}, \%$ & $\mathrm{CO}_{2}, \%$ & $\mathrm{CCl}_{4}, \%$ & $\mathrm{C}_{2} \mathrm{~F}_{4} \mathrm{Br}_{2}, \%$ & $\mathrm{~T}, \mathrm{~K}$ & $\mathrm{p}, \mathrm{bar}$ \\
\hline Mixture1 & 6.7 & 3.3 & -- & -- & -- & $1030-1400$ & $4.3-5.8$ \\
\hline Mixture2 & 6.7 & 3.3 & 10 & -- & -- & $1045-1300$ & $4.3-5.5$ \\
\hline Mixture3 & 6.7 & 3.3 & -- & 2 & -- & $1180-1400$ & $4.3-4.4$ \\
\hline Mixture4 & 6.7 & 3.3 & -- & -- & 1 & $1130-1400$ & $5.6-5.8$ \\
\hline
\end{tabular}

Examples of characteristic oscillograms are presented in Fig. 1 - pressure profiles (a) and nonequilibrium radiation in the $310 \mathrm{~nm}$ (b) and $411 \mathrm{~nm} \mathrm{(c)} \mathrm{regions} \mathrm{(for} \mathrm{another}$ wavelengths the signal is similar), upon ignition of $\mathrm{H}_{2} / \mathrm{O}_{2}$ mixtures without an inhibitor and with the addition of $2 \% \mathrm{CCl}_{4}$ at similar temperatures behind shock waves. At the moment of ignition, characterized by a sharp rise in pressure, a peak emission signal appears at all wavelengths.

\section{Results}

It is clearly seen from the Fig. 1 the addition of an inhibitor does substantially increase the ignition delay and, at the same time, reduce the intensity of nonequilibrium emission of the $\mathrm{OH}^{*}$ radical at $310 \mathrm{~nm}$. However, in the region of $411 \mathrm{~nm}$, on the contrary, there is a significant increase in nonequilibrium emission.

Similar oscillograms were obtained in all the mixtures studied at different temperatures from 1050 to $1400 \mathrm{~K}$. In additional series of experiments the absorption of intense radiation from a gas discharge lamp DKSSh-150 (having a brightness temperature of about $4000 \mathrm{~K}$ in these spectral regions) against a background of the signal was measured. Additional 
emission was detected from the source, which indicated a highly super-equilibrium character of the observed emission, with an effective excitation temperature above the brightness temperature of the source.
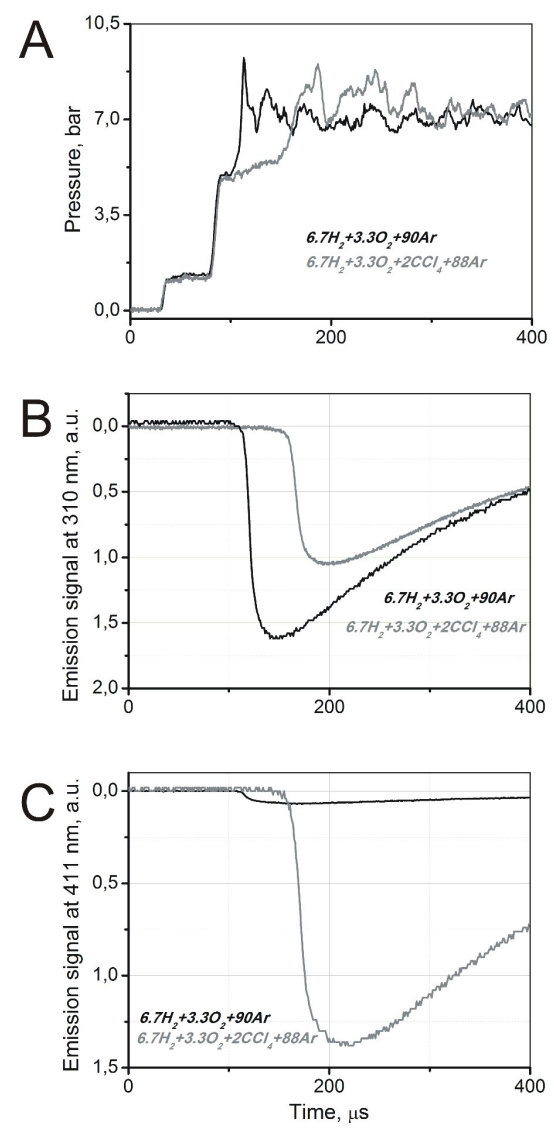

Fig. 1. Characteristic oscillograms of pressure profiles (a), and nonequilibrium radiation at $310 \mathrm{~nm}$ (b) and $411 \mathrm{~nm}(\mathrm{c})$ regions, at ignition of $\mathrm{H}_{2} / \mathrm{O}_{2}$ mixtures without an inhibitor $\left(p_{5}=5.2 \mathrm{~atm}, T_{5}=1215\right.$ $\mathrm{K})$ and with $2 \% \mathrm{CCl}_{4}\left(p_{5}=5 \mathrm{~atm}, T_{5}=1250 \mathrm{~K}\right)$.

The spectral dependencies of detected nonequlibrium radiation are shown in Fig. 2. It is seen from this figure that at $310 \mathrm{~nm}$, corresponding to the chemiluminescence signal of the $\mathrm{OH} *$ radical, in the temperature range studied, the presence of additives leads to a slight decrease in the observed amplitude of the signal in $2-3$ times, while at a wavelength of 210 $\mathrm{nm}$, with the addition of $\mathrm{CO}_{2}$, the amplitude of the signal did not change, and with the addition of $\mathrm{C}_{2} \mathrm{~F}_{4} \mathrm{Br}_{2}$ and $\mathrm{CCl}_{4}$, an increase in the signal of emission was observed almost the tenfold. But the most significant increase in nonequilibrium radiation was observed in a spectral range of 330-415 nm, where all additives, including inert $\mathrm{CO}_{2}$, led to an almost 20fold increase in the radiation intensity. 


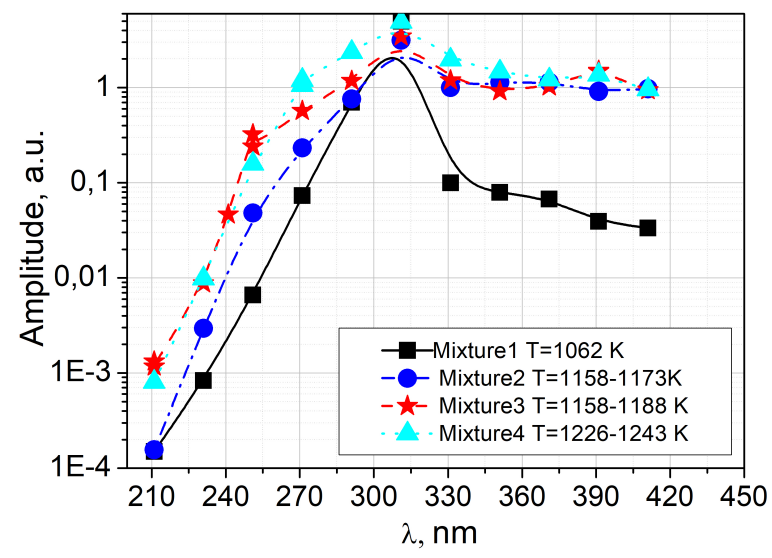

Fig. 2. Nonequlibrium emission spectra detected at ignition of hydrogen-oxygen mixtures.

\section{Discussion}

To analyse the possible mechanisms of amplification of nonequilibrium UV radiation with the addition of inhibitors to the hydrogen-oxygen mixture, numerical simulation of the kinetics of ignition of the investigated mixtures was carried out using the Chemkin code and kinetic mechanisms proposed in [12] for a hydrogen-oxygen mixture without additives and with the addition of $\mathrm{CO}_{2}$, and in a recent paper [5] - for mixtures with $\mathrm{CCl}_{4}$ additions. Both mechanisms are written in the form of "formal" kinetics, suggesting equilibrium in internal degrees of freedom of molecules. Note that for $\mathrm{C}_{2} \mathrm{~F}_{4} \mathrm{Br}_{2}$ no detailed kinetic combustion mechanism has been developed, therefore no numerical simulation has been performed.

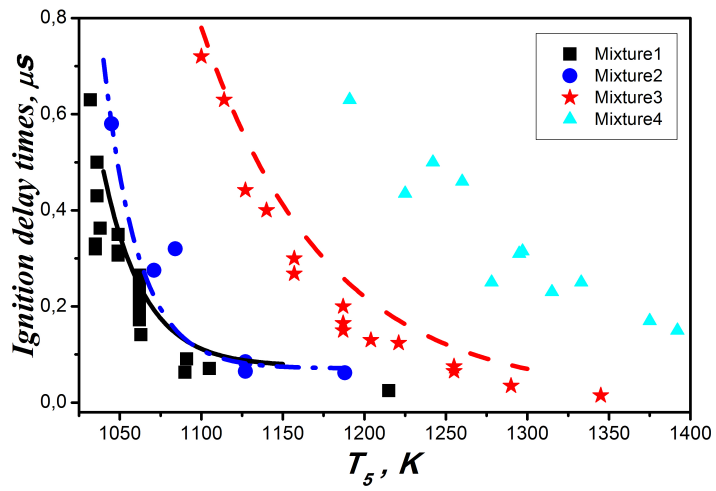

Fig. 3. Temperature dependences of ignition delay times. Points - experimental data, curves - the results of kinetic simulation.

The results of the calculations have shown that the theoretical model describes well the experimentally measured increase in ignition delay times with the addition of inhibitors (see Fig. 3). The addition of the $\mathrm{CCl}_{4}$ inhibitor leads to a significant decrease in the 
maximum concentration of the $\mathrm{HO}_{2}$ radical (in the ground state) and slightly increases the maximum concentration of hydrogen peroxide $\mathrm{H}_{2} \mathrm{O}_{2} . \mathrm{HO}_{2}$ is first consumed with addition of inhibitor in the reactions $\mathrm{Cl}+\mathrm{HO}_{2} \rightarrow \mathrm{HCl}+\mathrm{O}_{2} ; \mathrm{CCl}_{3}+\mathrm{HO}_{2} \rightarrow \mathrm{COCCl}_{2}+\mathrm{Cl}+\mathrm{OH}$ and secondly, it is less formed in the reaction $\mathrm{H}+\mathrm{O}_{2}(+\mathrm{M}) \rightarrow \mathrm{HO}_{2}(+\mathrm{M})$ due to consumption of $\mathrm{O}_{2}$ through the reactions $\mathrm{Cl}+\mathrm{O}_{2}=\mathrm{ClO}+\mathrm{O} ; \mathrm{CCl}_{3}+\mathrm{O}_{2}=\mathrm{COCl}_{2}+\mathrm{ClO}$. Thus, the observed chemiluminescence could hardly be associated with overexcited hydroperoxyl radicals. Hydrogen peroxide and water with addition of inhibitor are formed mainly through reactions $\mathrm{OH}+\mathrm{OH} \rightarrow \mathrm{H}_{2} \mathrm{O}_{2} ; \mathrm{OH}+\mathrm{OH} \rightarrow \mathrm{H}_{2} \mathrm{O}+\mathrm{H}$. The production of $\mathrm{OH}$ is in turn connected with atomic hydrogen via $\mathrm{H}+\mathrm{HO}_{2} \rightarrow \mathrm{OH}+\mathrm{OH} ; \mathrm{H}+\mathrm{O}_{2} \rightarrow \mathrm{O}+\mathrm{OH}$, whose formation is promoted by the reaction $\mathrm{Cl}+\mathrm{H}_{2} \rightarrow \mathrm{HCl}+\mathrm{H}$.

Thus, the observed increase in the intensity of chemiluminescence can be conventionally attributed to an increase in the concentration of electronically excited molecules $\mathrm{H}_{2} \mathrm{O}_{2}$ * or $\mathrm{H}_{2} \mathrm{O}^{*}$, which may indicate a redistribution of the reaction channels, but of course, in any way cannot lead to the observed effect of inhibition.

\section{Conclusion}

In this study, for the first time, a significant increase in the intensity of nonequilibrium radiation in the range of spectra $210-415 \mathrm{~nm}$ at ignition of hydrogen in the presence of inhibiting additions of halogenated hydrocarbons, was experimentally observed. Thus, the assumption of a mechanism for inhibiting the ignition of hydrogen by quenching excited radicals [7] is hardly justified, and the real mechanism of inhibition, as shown in [5,6], is the capture of the primary radicals by inhibitors.

This work was supported by the grant of the RNF - № 14-19-00025.

\section{References}

1. T. Fiala, T. Sattelmayer, J. Propul. Power 33, 490 (2016)

2. R.W. Schefer, W.D. Kulatilaka, B.D. Patterson, Combust. Flame 156, 1234 (2009)

3. M. Vanpee, R.J. Mainiero, Combust. Flame 34, 219 (1979)

4. P.J. Padley, Trans. Faraday Soc. 56, 449 (1960)

5. A. Drakon, A. Eremin, N. Matveeva, E. Mikheyeva, Combust. Flame 176, 592 (2017)

6. A. Drakon, A. Eremin, Combust. Sci. Technol. 190, 550 (2018)

7. O. Skrebkov, Combust. Theor. Model. 19, 138 (2015)

8. R.W. Getsinger, G.L. Schott, J. Chem. Phys. 43, 3237 (1965)

9. B.B. Darwent, V.J. Krasnansky, Symp. (Int.) Combust. 7, 3 (1958)

10. Z. Hong, K.-Y. Lam, R. Sur, S. Wang, D.F. Davidson, R.K. Hanson, Proc. Combust. Inst. 34, 565 (2013)

11. H. Kijewski, J. Troe, Int. J. Chem. Kin. 3, 223 (1971)

12. Z. Hong, D. Davidson, R. Hanson, Combust. Flame 158, 633 (2011) 